\title{
Travel Funds for University Library Staffs
}

Mrs. Pope is librarian, College of Engineering, and Dr. Thompson, director of libraries, University of Kentucky.

WEN A GROUP of librarians gathers in a smoke-filled room at a convention, one topic of conversation likely to turn up is: "Are you getting your expenses paid?" The nebulous information available under such circumstances has inspired the authors to find out just what conditions exist for official travel by university library employees. Accordingly, a questionnaire was sent to nine privately supported university libraries and to 73 libraries of land-grant colleges and universities and separate state universities (nonland-grant). Seventy-eight replies were received.

Questions asked covered only those problems which seem to turn up again and again in discussion of the travel problem and which, taken as a whole, could yield a fairly accurate picture of the national situation. The questions are listed below by number, and a summary of the answers follows in each instance:

IA. Is any specific sum budgeted for staff travel? Forty-three answered "yes," 32 "no," and three indicated they had no funds. Of the three libraries reporting no funds available, Alaska gave the reason that the distance is too great and air travel too expensive. The other two were a landgrant university and a separate state university.

IB. If so, please specify amount for 1948-
49. Among the 43 libraries with travel included as a budget item, $\$ 1325$ was high, $\$ 400$ the median, and $\$ 75$ low. In terms of quartiles, the sums budgeted may be grouped as follows: $\$ 75-\$ 150 ; \$ 200-\$ 400$; $\$ 400-\$ 600$; \$600-\$1 325. Although southeastern institutions fare slightly better than those in other parts of the country, location and total resources of the library seem to have little influence on the amount available for travel. For example, those midwestern university libraries which budget for travel all fall below the median, whereas eight of 14 southeastern libraries are above the median. The proximity of eastern university libraries to New York, Boston and Washington seems to have no effect on amounts set aside for travel, for the nine eastern institutions which budget for travel are scattered evenly throughout the series.

2. Is this carried on your budget or on the budget of some superior administrative officer? In 56 cases it was carried on the library budget, in Io cases on the budget of a superior administrative officer, and nine libraries gave no report. In six libraries in which no specific sum is allocated for traveling expenses, the head librarian charges this item against the general expense account, the contingent fund, or against the fund for supplies and equipment. Constituted funds of superior offcers are designated by such names as the chancellor's (or president's travel fund or the university travel fund. Two reports state that intrastate funds are applied 
against the library budget and interstate expenses are carried on the travel fund of a superior officer.

3A. Can you draw for travel from some other fund (e.g., fines, nonpersonal services, etc.) ? Eighteen answered "yes," 5 I "no," one reported that it is not necessary, and five did not report. Seven libraries reporting on the question explained that, if necessary, traveling expenses over and above the specific budgeted amount were available by requesting approval from the president or board and that all are honored so long as the request is reasonable.

$3 \mathrm{~B}$. If so, is this limited to any specific amount? In one instance it was limited to fines. Seventeen replied "no."

${ }_{4} \mathrm{~A}$. Are you limited to any specific amount for any one trip? Two replied "yes," 72 "no," and one did not report.

4B. If so, how much? One reported $\$ 75$, one reported $\$ 40$ (except head librarian, who enjoys the same travel privileges as president and other administrative officers; $\$ 40$ limit applies to all teaching personnel). While only two are limited to any specific sum, 30 reported specific limitations such as per diem arrangement, transportation and part transportation only, modes of travel, etc.

5. Do you have a per diem arrangement? Twenty-six answered "yes," 47 "no," while two did not report. Per diem ranges from a $\$ 2.25$ limit on meals within the state to a generous $\$ 12$ per day. The median runs about $\$ 6$, the sum that the federal government allows its employees for travel within the continental United States. In many state-supported institutions there is a substantial difference (up to \$3) between per diem for intrastate and interstate travel, and often as not, no expenses whatsoever are allowed for the former. One institution gives $\$ 7$ for trips to cities of less than 10,000, \$10 for cities of more than 10,000 . One institution uses a scale based on salaries, and another allows $\$ 9$ for each 24 hours at the point of destination in lieu of actual expenses.

6. Must you travel on state travel orders or buy tickets and itemize on expense account? Three answered that they travel on state travel orders; 62 that they buy tickets and itemize on the expense account; six reported following both procedures; and four did not report. Those answering "both" explained that intrastate traveling expenses must be done on state travel orders.

7. Do you have a form on which you submit expense accounts? Sixty answered "yes" to this question, I4 answered "no" and one failed to report.

8. For whom are travel funds available? In 39 instances the entire staff including the nonprofessional personnel qualify for traveling expenses; in 59 instances all of the professional staff qualifies; and at nine institutions only the chief librarian qualifies for travel funds. It is here that the disliked "limitations" appear in the guise of institutional rules and regulations and insuffcient funds.

9. Do you have a system for dividing available funds (e.g., certain trips for certain staff members, rotation of travel funds to conventions, use of funds for conventions and other business travel, etc.)? Sixteen reported "yes," and 55 indicated no definite systems, although certain principles were considered in the distribution of funds. Four did not report. Among the considerations involved in distribution of funds, I4 gave "discretion of director," and I 2 "rotation." Two reported that both of these factors were involved, and one stated that "rank" governed its policy. No explanations were received from 27 reporting no definite system, I 2 miscellaneous explanations were received, and three explained that expenses were available only for conventions. Conventions are the primary reason for travel in the majority of li- 
braries, but in two instances they are secondary. In one of these instances it is reported that business travel takes priority over conventions and in the other that trips for special purposes only are considered. One librarian had a definite recommendation about conventions: "No staff member to attend conventions more than once every five years. I mean, library conventions. They are poisonous."

Institutional restrictions and/or budget limitations govern all systems in whole or in part. In many cases priority is given those presenting papers and otherwise participating in the event under consideration. Where only the chief librarian qualifies for traveling expenses, it was found that in half of the cases that person collects the amount and either distributes it equally among those staff members making the trip or distributes it among those members who are using their cars for the transportation of the staff to and from the meeting.

Some of the typical systems for dividing travel funds are: (a) Estimate the cost, then plan the number and the persons. (b) Set aside a definite amount for each event, and divide among those attending, with speakers and officers receiving twice the allowance. (c) Request is judged by the importance of the trip. The librarian, his assistant, and sometimes one or two heads (those presenting papers or otherwise participating) are authorized to attend A.L.A. annual and midwinter conferences. In addition, two or three staff subject specialists are authorized to attend other meetings or to visit special libraries. (d) Expenses are covered for members presenting papers, otherwise participating, or representing the library officially. Other travel expenses are considered on the basis of merit. Schedule so that all can go every third year with at least part expenses paid. (f) Position and length of service are taken into consideration. (g) Rotate between senior- ity and rank. Other considerations in this case are benefit to be secured, e.g., heads are sent to library conferences; younger members are sent to state meetings; branch librarians are sent to special field meetings.

IOA. Can you use funds for all types of travel (e.g., library meetings both in and out of the state, nonlibrary meetings, inspection tours, etc.) ? Forty-eight answered "yes," I5 "no," six said that they did not know, and six did not report.

roB. If not, please explain. Some pertinent explanations are: Library meetings only; only available for out-of-state travel, but may include all types of travel; for all purposes except for trips to conventions; librarian as an administrative officer is allowed out-of-state travel, other staff members are restricted to state travel; prohibited from using state funds to travel to conventions; only for legitimate library meetings and/or necessary inspection tours; professional meetings and administrative travel only ; only library or library-related activities; library meetings or university business; in and out-of-state meetings only; library meetings in and out-of-state and inspection tours.

II. Do all staff members receive time off for all conventions of professional associations even though expenses may not be paid? Forty-two reported that only the professional staff receives time off, 26 reported that all full-time employees receive time off, seven reported "no policy." Maintenance of service governs this policy. Professional staff is given priority since its members are the ones most likely to benefit. In most instances in which the librarian reports "professional staff only" he adds the remark that others show no desire to attend.

I2. Is there any significant difference between the policy of your administration in assigning travel funds to the library and its policy in assigning funds to teaching departments and other agencies? Eight 
only said "yes," 6o said "no," seven did not report. Of those reporting "yes," five added that the library was more liberal in that it allowed a broader participation in professional activities. Three were of the opinion that the library suffered in consequence of the administration's policy.

13. What would you consider an ideal arrangement? Fourteen librarians consider their systems quite satisfactory. A few added that more funds would make it ideal. Six would like travel funds included in the library budget to be allocated at the discretion of the librarian and his aides. One deviated from the consensus in that he thought library travel expenses should be taken from the university travel budget. Four recommended adequate funds on a fluid budget as ideal. Four would like funds for at least two members of the professional staff, in addition to the librarian, both within and outside of the state. A somewhat different recommendation is that funds be available for all professional staff members to attend meetings at least every two years with a minimum of one-half of expenses paid. Two would be satisfied with sufficient funds to permit the chief librarian to attend all meetings and others to attend on a rotating basis. Other comments on ideal arrangements are summarized below.

A university-wide travel fund to which all university employees could turn for travel aid. Policies governing the fund could be formulated by a representative committee. Individual allotments could be made, within this framework, by an administrative officer.

Transportation and hotel bills would be the minimum the institution should contribute to staff members appearing on programs at national or regional professional meetings. Since the librarian is obliged to represent the library in at least one or two meetings each year, his full expenses should be paid.
A desirable arrangement would be to include in each year's budget an amount sufficient to send one member of the library's administrative staff to one library convention. The amount would be used in rotation by the librarian, the assistant librarian, the head of the cataloging department, and the head of the reference and circulation departments.

It would be ideal for the college to rent a private railway coach to take the staff to and from all library meetings.

A good policy would allow the administrator to determine, within the general policies of the individual institution, the stricture governing the apportionment of funds. The complexity of the strictures and the heirarchy of allowances would depend on several factors such as the amount of the total travel budget and the purpose of the allowance. Mere rank should not be overemphasized.

Expenses should be paid to all meetings where a person is on the program, gives papers or serves as a committee officer. Each member should attend national meetings as his turn comes up, and he should pay at least one-half the cost.

Contribution should be made to the actual expenses of library staff members attending regional or national meetings of professional interest and to the expenses incurred on trips of inspection motivated by the desire for definite information on administrative or technical problems.

No staff member should attend library conventions more than once every five years (supra). More travel funds should be allowed for visits to libraries and related institutions. Funds for travel should be divided into two parts: one for use of chief librarian, or for anyone he may designate; the other for specific purpose of giving every professional staff member a chance to travel.

A sufficiently large appropriation should 
be available to permit sending all professional staff members in rotation to national and regional meetings, plus all those holding offices or taking part in program.

All expenses should be paid for staff members: ( 1 ) participating in the scheduled program, (2) serving as officers of the association which is meeting, (3) traveling on library business.

A definite sum should be added to the salary with the understanding that staff members are expected to spend this sum each year for self-improvement and travel and participation in meetings. It would cause less red tape and broader participation. I would insist on a report on how this portion of the salary was used each year and would remove that part of the stipend if it were not being used for the purpose for which it was being granted.

\section{Summary and Conclusions}

While I 4 libraries included in this study revealed satisfaction with the systems under which they operate, many others indicated general satisfaction even though certain details may not be altogether to their liking. However, certain trends seem to be indicated by this study, and they may serve as guides for libraries which may wish to adjust certain details. The promptness with which the vast majority of the questionnaires were returned suggested definite interest on the part of library administrators in this problem, and it would seem worthwhile to repeat the study periodically.

The use of institutional funds for travel is a generally accepted practice in continental American universities. There seems to be no definite correlation between the amounts available and (I) the size and importance of the institution and (2) the distance from the New York-ChicagoWashington triangle. Privately supported institutions seem to fare no better, no worse than tax-supported institutions. The ma- jority of university libraries budget a specific sum for travel, although a significant proportion make no definite allotment. The most common practice seems to be to carry this money on the library budget, although a few libraries carry it on the budget of a superior administrative officer.

Only two institutions were limited to a specific amount for any one trip, but in one case no member of the teaching staff or librarian (except the head) is allowed more than \$40. Twenty-six of the institutions reporting indicated a per diem arrangement, but there is considerable variation in practice. Per diem seems to have a tendency to change more slowly than general appropriations and is likely as not to be insuffcient in time of inflation, excessive in times of deflation. Several librarians found fault with it.

State travel orders are not commonly used securing transportation, and it is interesting to note that there has been criticism of the system within the federal government, where they are compulsory. Comptrollers' offices have regularized reporting of expenses in the great majority of institutions by requiring expense accounts. The majority of reporting libraries can use their funds for all types of travel, but some states prohibit the use of state funds for trips to conventions.

The iniquitous practice of restricting funds for the use of higher members of the professional hierarchy has not yet been altogether wiped out. However, all but a very few libraries permit all full-time staff members to take time off to attend professional meetings. In several cases it was indicated that nonprofessional members of the staff have no desire to attend meetings. The authors would like to comment that wherever a little financial assistance to nonprofessional librarians makes no heavy inroads on the budget, encouragement to this group to attend meetings would seem to 
recommend itself as a recruiting device (unless we agree that conventions are poisonous). Definite systems for dividing available funds exist in one-fifth of the libraries reporting, but the consensus would seem to favor allotments on the basis of the importance of the trip to the institution. Although the library staff is sometimes likely to be at a disadvantage in certain matters such as sabbaticals, vacations, tenure and retirement, only a minor proportion seemed to feel that librarians fared more poorly than teachers in the matter of travel funds.

Perhaps the most significant trend indicated by this study is the increasing emphasis on broad participation in professional activities by all members of the staff, not merely the principal administrative officer. Within the memory of most of us, and still today in some libraries, the staff, including department heads, has rather supinely assumed that it had no rights to the travel funds, that only the head librarian was privileged to travel to conventions and to visit other libraries. Likely as not this idea was (or is) prevalent in institutions dominated by the straw-boss variety of administration. It might be replied that only the chief administrator of such a library reads papers or holds offices; but those libraries which have staffs of which they may be proud will be justified in giving time and stenographic help to any staff member who wishes to be active professionally, thus giving anyone a chance to justify a convention trip.

Another broad trend seems to be the application of common sense to the use of travel funds in that a trip may be taken whenever necessary. The notion that certain trips should be automatic seems to be going out of style. The hesitancy of a large proportion of libraries to budget a specific sum for travel is further evidence that administrators are inclined to appropri- ate money for travel as the need arises.

Regulations of state fiscal officers are a subject of general discontent, if the authors may go by rumor picked up in informal communications. No written statement has been received to this effect, but many colleagues who filled out the questionnaire have button-holed the authors privately and begun, "I didn't feel like putting this on the questionnaire, but our State Finance Department. ..." On the other hand we should consider the standpoints of the state fiscal officers. The regulation existing in many quarters that no intrastate travel funds are available except for attending to official business has been explained by one state official who said that the peregrinations of college of education professors would break the state in short order if financed from official funds. Similarly, while most state officers seem to have the reputation of being cooperative (even if not always competent) souls, they can still see the shillelagh of the woolhat politician being brandished in the distance. In general, freedom from higher administrative regulations would seem to be most desirable, but at the same time the librarian should put himself in the position of the fiscal officer who must approve his requisition.

Finally, it should be emphasized that libraries today are passing through the most prosperous period in their history. Our budgets still leave much to be desired, but we will probably have to pass through another cycle of depression, war, and boom, or at least (and preferably) depression and boom, before we can expect to attain many of our cherished ambitions. We must expect to be compelled to revise our budgets downward when some Black Friday in the 1950's comes along; but when it happens, we should not forget the principles of staff democracy and commonsense use of travel funds in which we are able to indulge today. 